\title{
Adjuvant treatment with thyrotropin alpha for remnant ablation in thyroid cancer
}

\author{
Bernadette Biondi \\ Melania Pulcrano \\ Loredana Pagano \\ Gaetano Lombardi
}

Department of Clinical and Molecular Endocrinology and Oncology, University of Naples Federico II, Naples, Italy
Correspondence: Bernadette Biondi Department of Clinical and Molecular Endocrinology and Oncology, University of Naples Federico II,Via S Pansini 5 . 80131 Naples

$\mathrm{Tel}+39$ 08I 7462432

$\mathrm{Fax}+3908 \mid 7463668$

Email bebiondi@unina.it, bebiondi@libero.it

\begin{abstract}
Various studies have demonstrated the safety and efficacy of recombinant human thyroid-stimulating hormone (rhTSH) for radioiodine remnant ablation. On this basis, rhTSH was approved in Europe for the radioiodine ablation of low-risk differentiated thyroid cancer (DTC) during thyroid hormone therapy with L-thyroxine (L-T4). Moreover, in December 2007, the US Federal Drug Administration approved the use of rhTSH for adjuvant treatment with radioiodine in patients with DTC without evidence of metastatic thyroid cancer. Quality of life was found to be better with rhTSH preparation than with L-thyroxine withdrawal, thereby resulting in benefits for society as a whole. Furthermore, rhTSH for radioiodine remnant ablation results in a longer effective radioiodine half-life within remnant thyroid tissue and a lower specific absorbed dose in the blood and exposure of bone marrow to X-rays. More studies are required to establish the amount of radioiodine to be administered especially in high-risk patients.
\end{abstract}

Keywords: thyroid cancer, thyrotropin, radioiodine $\left({ }^{131} \mathrm{I}\right)$ remnant ablation (RRA), quality of life, ray exposure

There is general agreement that total thyroidectomy is the initial treatment-of-choice for patients with differentiated thyroid cancer (DTC). ${ }^{1,2}$ Radioiodine $\left({ }^{131} \mathrm{I}\right)$ remnant ablation is recommended after thyroidectomy to destroy post-surgical residual thyroid tissue especially in patients at high-risk of recurrence and mortality. ${ }^{1,2}{ }^{131} \mathrm{I}$ ablation has two advantages: 1) it destroys any remaining microscopic tumoral foci; and 2) it eliminates all normal thyroid cells that would continue to produce thyroglobulin and confound interpretation of measurement of serum thyroglobulin $(\mathrm{Tg})$, which is a specific marker of recurrent or persistent disease. Consequently, this procedure improves the follow-up and treatment of patients with DTC by increasing the specificity and sensitivity of Tg monitoring and ${ }^{131} \mathrm{I}$ treatment. Moreover, ${ }^{131} \mathrm{I}$ administration decreases the frequency of recurrences and mortality. ${ }^{3-6}$

Elevated serum thyroid-stimulating hormone (TSH) levels (above $30 \mathrm{mU} / \mathrm{L}$ ) are necessary to ensure sufficient trapping and retention of ${ }^{131} \mathrm{I}$ by functioning thyroid tissue. ${ }^{1}$ Traditionally, the endogenous increase of TSH was achieved by withdrawal of thyroid hormone therapy (L-thyroxine; LT4) for 4 to 5 weeks, which induces clinical hypothyroidism. However, this short-term hypothyroid condition is associated with cognitive and physical impairment and alteration of quality of life in young and middle-aged patients. ${ }^{7,8}$ Moreover, withdrawal of LT4 can impair cardiac, cognitive and neurological function with consequent health risks especially for elderly people. . $^{7}$ Lastly, it may not increase TSH levels in cases of persistent thyroid hormone production by large thyroid remnants or functional metastases, in elderly patients, and in the presence of hypothalamic or pituitary disease or long-term steroid therapy. ${ }^{9-12}$

Recombinant human TSH (rhTSH) is a heterodimeric glycoprotein produced by recombinant DNA technology for the purpose of producing increased TSH levels without 
LT4 withdrawal and the consequent hypothyroidism. The use of rhTSH was initially limited to the field of DTC follow-up and was approved by the US Food and Drug Administration (FDA) in December 1998 for diagnostic use. Subsequently, rhTSH was found to be effective for ${ }^{131}$ I remnant ablation, ${ }^{13,14}$ and in February 2005, rhTSH was approved in Europe for the ${ }^{131}$ I ablation of low-risk DTC during thyroid hormone therapy with LT4. In December 2007 the FDA approved the use of rhTSH for adjuvant treatment with ${ }^{131} \mathrm{I}$ in patients with DTC without evidence of metastatic thyroid cancer.

Here we review the studies on rhTSH-aided ablation with the aim of addressing such open questions as the exact protocol of rhTSH administration and the dose of ${ }^{131} \mathrm{I}$ to obtain maximum effectiveness.

\section{RhTSH-aided ablation: literature analysis}

Table 1 lists the studies that evaluated the effectiveness of rhTSH in the adjuvant treatment for ${ }^{131}$ I remnant ablation in DTC patients. The criteria used to define successful thyroid ablation differed among studies from no visible uptake at whole body scan after rhTSH or undetectable basal and rhTSH-stimulated serum thyroglobulin. Despite these differences, there is general agreement that rhTSH for thyroid ablation gives results similar to those found after LT4 withdrawal.
The study by Perros et al was the first report on the use of rhTSH to increase ${ }^{131}$ I uptake for remnant ablation. ${ }^{15}$ Subsequently, the effect of rhTSH-aided ablation was evaluated in a prospective non-randomized trial of 10 patients with papillary cancer. ${ }^{16}$ The dose of ${ }^{131}$ I administrated varied between 30 and $250 \mathrm{mCi}$. The ablation rate was $100 \%$ when judged by the absence of visible uptake in the thyroid bed after diagnostic whole body scan 3 months after ablation. ${ }^{16}$ Another randomized study confirmed complete ablation after high doses of ${ }^{131} \mathrm{I}$ (approximately $108 \mathrm{mCi}$ ) by using TSH to stimulate ${ }^{131}$ I uptake for the ablation of remnant thyroid tissue. ${ }^{17}$

A subsequent retrospective study from the Memorial SloanKettering Cancer Center confirmed that a high dose of ${ }^{131} \mathrm{I}$ increased the rate of rhTSH-aided ablation in DTC patients. ${ }^{13}$ In this study, the rates of complete ablation did not differ significantly between a group of patients who were prepared by thyroid hormone withdrawal (THW) and a group of patients prepared by rhTSH when treated with $100 \mathrm{mCi}(84 \%$ in 45 euthyroid patients after rhTSH vs $81 \%$ in 42 hypothyroid patients $)^{13}$.

However, a prospective study by Pacini et al did not confirm these results. ${ }^{18}$ In this prospective randomized study in which $1.1 \mathrm{GBq}$ (30 mCi) was used as standard ablative activity, 162 DTC patients were randomized in three treatment arms: in the first arm, patients $(n=50)$ were treated by LT4 withdrawal (HYPO); in the second arm, patients

Table I Studies evaluating the efficacy of rhTSH for remnant ablation

\begin{tabular}{|c|c|c|c|c|c|c|c|c|}
\hline \multirow[t]{2}{*}{ Authors } & \multicolumn{2}{|l|}{ Patients (n) } & \multicolumn{2}{|c|}{ Stage of disease } & \multicolumn{2}{|c|}{ Dose of ${ }^{|3|} \mathbf{I}(\mathrm{mCi})$} & \multicolumn{2}{|l|}{ Outcome } \\
\hline & rhTSH & LT4W & rhTSH & LT4W & rhTSH & LT4W & rhTSH & LT4W \\
\hline $\begin{array}{l}\text { Robbins et al 200I } \\
\text { Prospective } \\
\text { randomized study }\end{array}$ & 10 & n.p. & TI-T4 & n.p. & $30-250$ & n.p. & $\begin{array}{l}100 \% \text { dWBS negative, } \\
60 \% \mathrm{Tg}<1.0\end{array}$ & \\
\hline $\begin{array}{l}\text { Pacini et al } 2002 \\
\text { Prospective }\end{array}$ & 70 & 50 & $\begin{array}{l}\text { TI-T4 } \\
\text { No-NI }\end{array}$ & $\begin{array}{l}\text { TI-T4 } \\
\text { No-NI }\end{array}$ & 30 & 30 & $\begin{array}{l}54 \% \text { dWBS negative } \\
86,8 \% \mathrm{Tg}<1.0\end{array}$ & $\begin{array}{l}\text { 84\% dWBS negative } \\
83 \% \mathrm{Tg}<1.0\end{array}$ \\
\hline randomized study & $\begin{array}{l}42 \text { rhTSH + } \\
\text { LT4WI }\end{array}$ & & $\begin{array}{l}\text { TI-T4 } \\
\text { N0-NI }\end{array}$ & & 30 & & $\begin{array}{l}78.5 \% \mathrm{dWBS} \text { negative } \\
84.8 \% \mathrm{Tg}<1.0\end{array}$ & \\
\hline $\begin{array}{l}\text { Robbins et al } 2002 \\
\text { Retrospective study }\end{array}$ & 45 & 42 & $\begin{array}{l}\text { TI-T4 } \\
\text { No-NI }\end{array}$ & $\begin{array}{l}\text { TI-T4 } \\
\text { No-NI }\end{array}$ & $110.4 \pm 65$ & $128.9 \pm 74$ & $81 \%$ dWBS negative & $84 \%$ dWBS negative \\
\hline $\begin{array}{l}\text { Barbaro et al } 2003 \\
\text { Non-randomized } \\
\text { prospective study }\end{array}$ & 16 & 19 & $\mathrm{I}-2$ & $\mathrm{I}-2$ & 30 & 30 & $\begin{array}{l}77 \% \text { dWBS negative } \\
86.5 \% \mathrm{Tg}<1.0\end{array}$ & $\begin{array}{l}76 \% \text { dWBS negative } \\
76 \% \mathrm{Tg}<1.0\end{array}$ \\
\hline $\begin{array}{l}\text { Pacini et al } 2006 \\
\text { Prospective } \\
\text { randomized study }\end{array}$ & 33 & 30 & $\begin{array}{l}\text { TI-T4 } \\
\text { No-NI }\end{array}$ & $\begin{array}{l}\text { TI-T4 } \\
\text { No-NI }\end{array}$ & 100 & 100 & $\begin{array}{l}75 \% \text { dWBS negative } \\
96 \% \mathrm{Tg}<2.0\end{array}$ & $\begin{array}{l}86 \% \text { dWBS negative } \\
86 \% \mathrm{Tg}<2.0\end{array}$ \\
\hline $\begin{array}{l}\text { Pilli et al } 2007 \\
\text { Prospective }\end{array}$ & 36 & n.p. & $\begin{array}{l}\text { TI-T4 } \\
\text { No-NI }\end{array}$ & $\begin{array}{l}\text { TI-T4 } \\
\text { No-NI }\end{array}$ & 50 & n.p. & $\begin{array}{l}88.9 \% \text { dWBS negative } \\
78.9 \% \mathrm{Tg}<1.0\end{array}$ & \\
\hline randomized study & 36 & & $\begin{array}{l}\text { TI-T4 } \\
\text { No-NI }\end{array}$ & $\begin{array}{l}\text { TI-T4 } \\
\text { No-NI }\end{array}$ & 100 & n.p. & $\begin{array}{l}88.9 \% \text { dWBS negative } \\
67 \% \mathrm{Tg}<1.0\end{array}$ & \\
\hline
\end{tabular}

n.p. $=$ not performed.

Abbreviations: rhTSH, recombinant human thyroid-stimulating hormone; dWBS, diagnostic whole body scanner; LT4W, levo-thyroxine withdrawal; Tg, serum thyroglobulin. 
$(n=42)$ were treated by LT4 withdrawal combined with rhTSH (HYPO + rhTSH); in the third arm, patients $(\mathrm{n}=70)$ were stimulated with rhTSH in euthyroidism (EU + rhTSH). The follow-up was performed 6 to 10 months post ablation. When the criterion for successful ablation was no uptake on the thyroid bed on diagnostic whole body scan, the rate of successful ablation was similar in the HYPO and HYPO + rhTSH groups $(84 \%$ and $78.5 \%$, respectively) but significantly lower $(54 \% \mathrm{p}<0.01)$ in the EU + rhTSH group. ${ }^{18}$ On the contrary when successful ablation was defined as no visible thyroid bed uptake on diagnostic whole body scan or undetectable serum Tg after rhTSH, the success rates were similar (95\% vs 74\%). However, the reduced rate of ablation in the EU group may be explained by the protocol of ${ }^{131} \mathrm{I}$ administration used by Pacini et al. ${ }^{18}$ Indeed, ablative ${ }^{131} \mathrm{I}$ administration was delayed by $24 \mathrm{~h}$ and it was delivered $48 \mathrm{~h}$ after the second injection of rhTSH. Therefore, the authors suggested that the dose of ${ }^{131} \mathrm{I}$ be increased or that different protocols of rhTSH administration be used to obtain a satisfactory rate of rhTSH-aided thyroid ablation.

An international randomized controlled trial showed that the efficacy of rhTSH for ablation was similar to that of LT4 withdrawal with $100 \%$ ablation after $3.7 \mathrm{GBq}(100 \mathrm{mCi}) .{ }^{14}$ The predefined primary criterion for successful ablation was "no visible uptake in the thyroid bed, or a visible uptake less than $0.1 \%$ " on neck scans performed 8 months after therapy, and was satisfied in $100 \%$ of patients in both groups. A secondary criterion for ablation, a rhTSH-stimulated serum thyroglobulin concentration less than $2 \mathrm{ng} / \mathrm{mL}$, was fulfilled by 23 of 24 (96\%) euthyroid rhTSH patients and 18 of 21 (86\%) hypothyroid patients $(\mathrm{p}=0.2341)$. In this randomized prospective ablation trial, all rhTSH patients had an iodine excretion below $200 \mu / \mathrm{L}$, indicating the absence of overt iodine excess.

Only two studies have evaluated the efficacy of rhTSH for remnant ablation with lower ${ }^{131} \mathrm{I}$ doses. ${ }^{19,20}$ A recent study by Pilli et al showed that $1850 \mathrm{MBq}(50 \mathrm{mCi}){ }^{131} \mathrm{I}$ had a similar success rate to $3700 \mathrm{MBq}(100 \mathrm{mCi})$ in 72 patients prepared with rhTSH for thyroid ablation. ${ }^{19}$ This prospective, randomized study showed that $3700 \mathrm{MBq}{ }^{131} \mathrm{I}$ is associated with high rates of successful thyroid ablation after rhTSH preparation and that similar ablation rates $(88.9 \%)$ were obtained with lower ${ }^{131}$ I activity (1850 MBq). These results were obtained when the criterion of successful ablation was defined as no visible uptake at the 6-to 8-month control diagnostic ${ }^{131}$ I whole body scan after rhTSH stimulation, and also when the criterion of successful ablation was undetectable $(1 \mathrm{ng} / \mathrm{mL})$ rhTSH-stimulated serum Tg. Furthermore, successful ablation was also obtained in patients with nodal metastases.
Lastly, the dosimetric study showed that thyroid uptake was similar in patients treated with 1850 or $3700 \mathrm{MBq}$.

Since thyroid hormones are an important source of iodine and may interfere with ${ }^{131} \mathrm{I}$ uptake during thyroid ablation, Barbaro et al suggested LT4 therapy be discontinued before rhTSH injection. ${ }^{20}$ They compared ablation obtained with doses of $30 \mathrm{mCi}$ in 2 groups of DTC patients: one group was prepared by hypothyroidism and the other group was prepared by rhTSH stimulation. In the rhTSH group, LT4 therapy was interrupted for 4 days starting the day before the first injection. In the rhTSH group, urinary iodine excretion was significantly lower than in a control group of euthyroid subjects who rececived rhTSH stimulation. One year later, patients underwent a whole body scan with a tracer dose of ${ }^{131}$ I and serum Tg was measured using rhTSH with the same protocol in both groups. The percentage of ablation (undetectable Tg and a negative whole body scan) was $81.2 \%$ in patients treated with rhTSH and $76 \%$ in patients treated by L-T4 withdrawal.

Similarly, Pitoia et al suggested replacing LT4 with LT3 therapy to maintain the euthyroid state and to minimize the iodine pool during rhTSH preparation. ${ }^{21}$ Indeed, LT3 has an iodine content 5 -fold less than LT4. ${ }^{21}$

\section{RhTSH-aided ablation: ${ }^{13 !}$ I dosimetry, safety and cost}

Because ${ }^{131}$ I activity is associated with such important risks as bone marrow depression and pulmonary fibrosis, several dosimetric studies have been performed to evaluate the absorbed dose in the blood (a surrogate for bone marrow) and ${ }^{131}$ I activity in the lung to determine the minimum effective dose to reduce the these risks. It has been reported that a dose of $2 \mathrm{~Gy}$ of radiation in the blood is dose-limiting, ${ }^{22}$ whereas $3 \mathrm{GBq}$ in the lung in $24 \mathrm{~h}$ is the safety limit to avoid pulmonary fibrosis. ${ }^{23}$

An international, prospective, randomized study compared the iodine biokinetics, dosimetry and the effectiveness of ablation therapy with $100 \mathrm{mCi}$ in DTC after rhTSH stimulation or LT4 withdrawal. ${ }^{24}$ Iodine biokinetics differed between the two groups of patients. ${ }^{24}$ In fact, in the euthyroid state, renal clearance of iodine was $50 \%$ faster than in hypothyroidism. ${ }^{31}$ Indeed, fractional ${ }^{131} \mathrm{I}$ uptake into thyroid remnants was lower after rhTSH stimulation than after LT4 withdrawal. ${ }^{24}$ However, this reduction was partially compensated for by an increased half-life of ${ }^{131} \mathrm{I}$ in thyroid cells after rhTSH stimulation. ${ }^{24}$ rhTSH-treated patients showed a longer effective ${ }^{131} \mathrm{I}$ half-life within remnant thyroid tissue, and the residence times of the radioisotope were comparable in the two groups. ${ }^{24}$ Moreover, the specific absorbed dose in the blood was significantly lower (one-third) after rhTSH preparation, suggesting that 
higher ${ }^{131} \mathrm{I}$ activities might be safely administered after rhTSH stimulation. ${ }^{24}$ Finally, another study confirmed that the bone marrow absorbed dose remained under 2 Gy after rhTSH-aided administration of high activities of ${ }^{131} \mathrm{I} .{ }^{25}$ Moreover, patients prepared with rhTSH had a better quality of life than hypothyroid patients. ${ }^{14,29,30}$ RhTSH-aided ablation was well tolerated with no important side effects, and it can be useful in elderly patients and in patients with associated co-morbidities without increasing the risk of cardiac, cerebrovascular, pulmonary or neurological complications. , $26,27^{2}$

Finally, a recent study compared the cost-effectiveness of ablation after rhTSH stimulation or LT4 withdrawal. The additional cost of rhTSH procurement and administration was considered justified in relation to the clinical benefits and cost offsets such as avoidance of hypothyroidism, increased work productivity and quality life, reduced discharge from radioprotection and period of sick leave. ${ }^{28}$ These observations were recently confirmed by Borget et $\mathrm{al}^{30}$ who found that rhTSH can decrease the duration of sick leave, and that its high cost is compensated for by benefits to patients and society with a modest net cost. ${ }^{30}$

\section{RhTSH-aided ablation: advantages and limits}

There is general agreement that rhTSH-aided ablation is effective and safe. Various studies have confirmed the efficacy of rhTSH in aiding ablation and show that rhTSH preparation is more beneficial than LT4 withdrawal ${ }^{32}$ in terms of quality of life $\mathrm{e}^{1,4,29,30}$ and well-being and avoids the important side effects of short-term hypothyroidism. Moreover, rhTSH for remnant ablation decreases exposure of bone marrow to X-rays.

Several questions are still open, namely, the amount of ${ }^{131}$ I to be administered and the effect of iodine intake. More studies are required to evaluate whether rhTSH can be used effectively for remnant ablation in high risk patients with outcomes at least comparable to those seen with ablation after thyroxine withdrawal.

\section{Disclosures}

The authors have no conflicts of interest to disclose.

\section{References}

1. Cooper DS, Doherty GM, Haugen BR, et al. The American Thyroid Association Guidelines Taskforce. Management guidelines for patients with thyroid nodules and differentiated thyroid cancer. Thyroid. 2006;16(2):109-42.

2. Pacini F, Schlumberger M, Dralle H, Elisei R, Smit JWA, Wiersinga W. The European Thyroid Cancer Taskforce. European consensus for the management of patients with differentiated thyroid carcinoma of the follicular epithelium. Eur J Endocrinol. 2006;154(6):787-803.
3. Mazzaferri EL, Kloos RT. Clinical review 128: Current approaches to primary therapy for papillary and follicular thyroid cancer. $J$ Clin Endocrinol Metab. 2001;86(4):1447-63.

4. Robbins R, Schlumberger M. The evolving role of (131)I for the treatment of differentiated thyroid carcinoma. $\mathrm{J} \mathrm{Nucl} \mathrm{Med.}$ 2005;46 (Suppl 1):28S-37S.

5. Wartofsky L, Sherman SI, Gopal J, Schlumberger M. Hay ID. The use of radioactive iodine in patients with papillary and follicular thyroid cancer. J Clin Endocrinol Metab. 1998;83(12):4195-203.

6. Sawka AM, Thephamongkhol K, Brouwers M, Thabane L, Browman G, Gerstein HC. Clinical review 170: A systematic review and metaanalysis of the effectiveness of radioactive iodine remnant ablation for well-differentiated thyroid cancer. J Clin Endocrinol Metab. 2004;89(8):3668-76.

7. Schroeder PR, Haugen BR, Pacini F, et al. A comparison of short-term changes in health-related quality of life in thyroid carcinoma patients undergoing diagnostic evaluation with recombinant human thyrotropin compared with thyroid hormone withdrawal. J Clin Endocrinol Metab. 2006;91(3):878-84.

8. Duntas LH, Biondi B. Short-term hypothyroidism after Levothyroxinewithdrawal in patients with differentiated thyroid cancer: clinical and quality of life consequences. Eur J Endocrinol. 2007;156(1):13-9.

9. Rudavsky AZ, and Freeman LM. Treatment of scan-negative, thyroglobulin-positive metastatic thyroid cancer using radioiodine I131 and recombinant human thyroid-stimulating hormone [clinical case seminar]. J Clin Endocrinol Metab. 1998;82(1):11-4.

10. Adler ML, Macapinlac HA, Robbins RJ. Radioiodine treatment of thyroid cancer with the aid of recombinant human thyrotropin. Endocr Pract. 1998;4(5):282-86.

11. Jarzab B, Handkiewicz-Junak D, Gawkowska-Suwinska M. Recombinant human TSH in the diagnosis and treatment of disseminated differentiated thyroid cancer. Nucl Med Rev Cent East Eur. 2000;3(2):82-8.

12. Luster M, Lassmann M, Haenscheid M, Michalowski U, Incerti C, Reiners C. Use of recombinant human thyrotropin before radioiodine therapy in patients with advanced differentiated thyroid carcinoma. J Clin Endocrinol Metab. 2000;85(5):3640-45.

13. Robbins RJ, Larson SM, Sinha N, et al. A retrospective review of the effectiveness of recombinant human TSH as preparation for radioiodine thyroid remnant ablation [brief communication]. $J$ Nucl Med. 2002;43(11):1482-88.

14. Pacini F, Ladenson PW, Schlumberger M, et al. Radioiodine ablation of thyroid remnants after preparation with recombinant human thyrotropin in differentiated thyroid carcinoma: results of an international, randomized, controlled study. J Clin Endocrinol Metab. 2006;91(3):926-32.

15. Perros P. Recombinant human thyroid-stimulating hormone (rhTSH) in the radioablation of well-differentiated thyroid cancer: preliminary therapeutic experience. J Endocrinol Invest. 1999;22 (Suppl):30-4.

16. Robbins RJ, Tuttle RM, Sonenberg M, et al. Radioiodine ablation of thyroid remnants after preparation with recombinant human thyrotropin. Thyroid. 2001;11(9):865-69.

17. Berg G, Lindstedt G, Suurküla M, Jansson S. Radioiodine ablation and therapy in differentiated thyroid cancer under stimulation with recombinant human thyroid-stimulating hormone (rhTSH). J Endocrinol Invest. 2002;25(4):44-52.

18. Pacini F, Molinaro E, Castagna MG, et al. Ablation of thyroid residues with $30 \mathrm{mCi}$ I131: a comparison in thyroid cancer patients prepared with recombinant human TSH or thyroid hormone withdrawal. J Clin Endocrinol Metab. 2002;87(9):4063-68.

19. Pilli T, Brianzoni E, Capoccetti F, et al. A comparison of 1850 (50 mCi) and $3700 \mathrm{MBq}(100 \mathrm{mCi}) 131$-iodine administered doses for recombinant thyrotropin-stimulated postoperative thyroid remnant ablation in differentiated thyroid cancer. J Clin Endocrinol Metab. 2007;92(9):3542-46.

20. Barbaro D, Boni G, Meucci G, et al. Radioiodine treatment with $30 \mathrm{mCi}$ after recombinant human thyrotropin stimulation in thyroid cancer: effectiveness for postsurgical remnants ablation and possible role of iodine content in L-thyroxine in the outcome of ablation. J Clin Endocrinol Metab. 2003;88(9):4110-15. 
21. Pitoia F, Degrossi OJ, Niepomniszcze H. Why should the radioiodine dose be different in patients with differentiated thyroid carcinoma prepared with recombinant human TSH? Eur J Nucl Med Mol Imaging. 2004;31(6):924.

22. Scala RJ, Biologic effects of ionizing radiation. In: Early PJ, Sodee BD, (eds). St Louis, MO Mosby Principles and practice of nuclear medicine. 1995; p.123-7.

23. Benua RS, Cicale NR, Sonenberg M, Rawson RW. The relation of radioiodine dosimetry to results and complications in the treatment of metastatic thyroid cancer. AJR Am J Roentgenol. 1962;87:171-82.

24. Hänscheid H, Lassmann M, Luster M, et al. Iodine biokinetics and dosimetry in radioiodine therapy of thyroid cancer: procedures and results of a prospective international controlled study of ablation after rhTSH or hormone withdrawal. J Nucl Med. 2006;47(4):648-54.

25. de Keizer B, Hoekstra A, Konijnenberg MW, et al. Bone marrow dosimetry and safety of high 1131 activities given after recombinant human thyroid-stimulating hormone to treat metastatic differentiated thyroid cancer. J Nucl Med. 2004;45(9):1549-54.

26. Luster M, Lippi F, Jarzab B, et al. rhTSH-aided radioiodine ablation and treatment of differentiated thyroid carcinoma: a comprehensive review. Endocr Relat Cancer. 2005;12(1):49-64.
27. Duntas LH, Cooper DS. Review on the occasion of a decade of recombinant human TSH: prospects and novel uses. Thyroid. 2008;18(5):509-16.

28. Mernagh P, Campbell S, Dietlein M, Luster M, Mazzaferri E, Weston AR. Cost-effectiveness of using recombinant human TSH prior to radioiodine ablation for thyroid cancer, compared with treating patients in a hypothyroid state: the German perspective. Eur $J$ Endocrinol. 2006;155(3):405-14.

29. Luster M, Felbinger R, Dietlein M, Reiners C. Thyroid hormone withdrawal in patients with differentiated thyroid carcinoma: a one hundred thirty-patient pilot survey on consequences of hypothyroidism and a pharmacoeconomic comparison to recombinant thyrotropin administration. Thyroid. 2005;15(10):1147-55.

30. Borget I, Corone C, Nocaudie M, et al. leave for follow-up control in thyroid cancer patients: comparison between stimulation with Thyrogen and thyroid hormone withdrawal. Eur J Endocrinol. 2007;156(5):531-8.

31. Ladenson PW, Braverman LE, Mazzaferri EL, et al. Comparison of administration of recombinant human thyrotropin with withdrawal of thyroid hormone for radioactive iodine scanning in patients with thyroid carcinoma. N Engl J Med. 1997;337(13):888-96.

32. Haugen BR, Cooper DS, Emerson CH, et al. Expanding indications for recombinant human TSH in thyroid cancer. Thyroid. 2008;18(7):687-94. 
